\title{
Evaluation of bulk-fill systems: microtensile bond strength and non-destructive imaging of marginal adaptation
}

\author{
Bruna Marin FRONZA ${ }^{(a)}$ \\ Patricia MAKISHI(a) \\ Alireza SADR ${ }^{(\mathbf{b})}$ \\ Yasushi SHIMADA(c) \\ Yasunori SUMI(d) \\ Junii TAGAMI(c) \\ Marcelo GIANNINI (a) \\ (a) Universidade Estadual de \\ Campinas - Unicamp, Piracicaba Dental \\ School, Department of Restorative Dentistry, \\ Piracicaba, SP, Brazil. \\ (b) University of Washington, School of \\ Dentistry, Department of Restorative \\ Dentistry, Seattle, WA, USA. \\ (c)Tokyo Medical and Dental University, \\ Graduate School, Department of Restorative \\ Sciences, Tokyo, Japan. \\ (d)National Center for Geriatrics and \\ Gerontology, National Hospital for Geriatric \\ Medicine, Department of Advanced \\ Medicine, Obu City, Japan.
}

Declaration of Interest: The authors certify that they have no commercial or associative interest that represents a conflict of interest in connection with the manuscript.

Corresponding Author:

Bruna Marin Fronza

E-mail: bruna.fronza@hotmail.com

Submitted: January 29, 2018

Accepted for publication: April 23, 2018

Last revision: July 03, 2018
Abstract: The objective of this study was to investigate microtensile bond strength (MTBS) and interfacial adaptation (IA) of bulk-fill restorative systems bonded to dentin in Class-I-preparations. Box-shaped preparations (4-mm-long, 3-mm-wide, 2-mm-high) made in extracted molars, and Teflon matrix with the same dimensions positioned over the occlusal surface were restored, providing a total of 4-mm composite depth using three bulk-fill restorative systems: Tetric EvoCeram Bulk Fill with Tetric N-Bond (TEC/TNB), SureFil SDR Flow with XP Bond (SDR/XPB) and Filtek Bulk Fill Flowable Restorative with Scotchbond Universal (FBF/SBU); or incrementally restored with a conventional restorative system: Herculite Classic with OptiBond FL (HER/OBF). The specimens were sectioned into beams and the MTBS measured after 24-hours or one-year storage. For evaluation of IA, round-tapered tooth preparations (3-mm-diameter, 1.5-mm-deep) were made, restored with each material and their cross-sectional images were obtained after 24-hours using optical coherence tomography (OCT). The gap percentage for each restoration system was calculated using image analysis software. MTBS for both storage periods: HER/OBF=TEC/TNB=SDR/XPB $>F B F / S B U$ (ANOVA, Tukey's post-hoc, $P<0.05$ ) differed significantly among groups, which values were significantly reduced after one-year. SDR/XPB showed comparatively lesser gap formation at the tooth-interface after 24 hours (ANOVA, Dunnett's T3 post-hoc, $P<0.05$ ). For deeper restorations, bond strength of TEC/TNB and SDR/XPB can be equal to that of HER/ $\mathrm{OBF}$ after 24-hours and one-year; however, in a shallower preparation, $\mathrm{SDR} / \mathrm{XPB}$ showed greater initial interfacial adaptation.

Keywords: Dentin; Composite Resins; Dental Cements; Tomography, Optical Coherence.

\section{Introduction}

Dental composites consist of the combination of silanized fillers and a resin matrix, which is polymerized through free radical reaction, activated by visible light. ${ }^{1}$ These materials shrink during polymerization, resulting in a volumetric reduction. ${ }^{2}$ This volume loss during the rapid polymerization along with elastic modulus acquirement generate internal stresses that may affect the marginal integrity of composite restorations and possibly lead to debonding from the surrounding tooth structure, and thus gap formation. ${ }^{2,3}$ 
Efforts have been made to minimize shrinkage stress of composites, including using incremental filling techniques. ${ }^{4,5}$ Studies have shown that these techniques reduce cuspal deflection, incidence of enamel cracks or fractures, premature gap formation at the resindentin interface and postoperative sensitivity. ${ }^{4,6,7}$ The rationale of the incremental technique is to avoid joining opposite walls with a large volume of composite. Instead, shrinkage stress is minimized when there are fewer bonded prepared walls involved during the polymerization, thus reducing the C-factor. In addition, by incrementally curing either $2-\mathrm{mm}$ thick increments, a higher degree of conversion is expected due to lower light attenuation. ${ }^{6,8}$

Among composites available, there is a growing interest in bulk-fill composites. These products are designed to replace the need for incremental layering, providing simple and fast clinical procedures. According to manufacturers, this new category of composites is intended to be applied as a single incremental application of 4 to $6 \mathrm{~mm}$ thick layer. This simplified strategy is said to be attributed to increased composite translucency, allowing greater light transmission with depth, and to the addition of more reactive photoinitiators. ${ }^{9,10}$ In addition, these materials are claimed to have low shrinkage stress due to inclusion of proprietary stress reliever molecules and polymerization modulators.,11

The purpose of the present study was to evaluate the microtensile bond strength (MTBS) and interfacial adaptation (IA) of three bulk-fill composites used with their respective adhesive systems, compared to the use of a conventional restorative system, consisting of a conventional composite and a three-step, etchand-rinse adhesive system bonded to tooth substrate, in Class I preparations. The null hypotheses tested were that there would be no significant difference in a. microtensile bond strength or $b$. interfacial adaptation between bulk-fill composites and a conventional restorative system, when bonded to tooth substrate.

\section{Methodology}

\section{Materials and experimental groups}

Four commercial composites with their respective bonding agents were evaluated: one high-viscosity, conventional composite, Herculite Classic used with a three-step etch-and-rinse adhesive system, OptiBond FL (HER/OBF; Kerr Corporation, Orange, USA), used as control; one high-viscosity bulk-fill composite, Tetric EvoCeram Bulk Fill, used with a two-step etchand-rinse adhesive system, Tetric N-Bond (TEC/TNB; Ivoclar Vivadent AG, Schaan, Liechtenstein); and two low-viscosity, bulk-fill composites: SureFil SDR Flow used with a two-step etch-and-rinse adhesive system, XP Bond (SDR/XPB; Dentsply Caulk, Milford, USA), and Filtek Bulk Fill Flowable Restorative, used with a one-step self-etch adhesive system, Scotchbond Universal (FBF/SBU; 3M ESPE, St. Paul, , USA).

Materials specifications' are listed in Table 1. Composites and their adhesive systems were used according to the manufacturer's instructions and cured using a multiwavelength light emitting diode curing unit (VALO, Ultradent Products Inc., South Jordan, USA). The irradiance of this unit was between 350 and $550 \mathrm{~nm}$ at $995 \pm 2 \mathrm{~mW} / \mathrm{cm}^{2}$, which was determined using a laboratory-grade spectral radiometer (USB 2000, Ocean Optics, Dunedin, USA) attached to a 7.62 $\mathrm{cm}$ diameter integrating sphere (CTSM-LSM-60-SF, Labshpere Inc., Sutton, USA), used with specific software (Spectra Suite v5.1, Ocean Optics Inc.).

\section{Specimen preparation}

Fifty-six freshly extracted, caries-free, human third molars were collected and stored at $4^{\circ} \mathrm{C}$, for up to 4 months after extraction. Teeth were used according to the guidelines of the local Ethics Committee, under protocol number $015 / 2014$. The roots were cut using a diamond blade (Isomet Diamond Wafering Blades, no. 11-4244, Buehler Ltd., Lake Buff, USA) under water cooling and the occlusal enamel was slightly polished with a 1500-grit silicon carbide paper until a flat area was obtained. This process was aimed to eliminate any possible superficial enamel cracks, and create a flat enamel surface for standard preparations.

\section{Microtensile bond strength (MTBS) testing}

Forty teeth were randomly selected for MTBS testing. Standardized, box-shaped Class I preparations $(4 \mathrm{~mm}$ mesio-distal width $\times 3 \mathrm{~mm}$ bucco-lingual width $\times 2 \mathrm{~mm}$ deep), with margins located in the occlusal enamel and the cavity floor located in the dentin were prepared using a diamond bur (FG\#3145, KG Sorensen, Cotia, 
Table 1. Restorative systems used in this study and their respective manufacturer's information.

\begin{tabular}{|c|c|c|c|}
\hline Material & Brand (lot number) & Manufacturer & Composition $^{a}$ \\
\hline \multirow{2}{*}{$\begin{array}{l}\text { High-viscosity } \\
\text { conventional } \\
\text { composite resin }\end{array}$} & Herculite Classic, & \multirow{5}{*}{$\begin{array}{l}\text { Kerr Corporation, } \\
\text { Orange, USA }\end{array}$} & $\begin{array}{l}\text { Composite: Bis-GMA, TEGDMA, camphorquinone, activator, amine, } \\
\text { iron oxide pigments, borosilicate-aluminum glass, colloidal silica. }\end{array}$ \\
\hline & $\begin{array}{l}\text { Shade A2; } \\
-400936\end{array}$ & & Filler loading $79 \mathrm{wt} \%$ and 59 vol\% \\
\hline \multirow{3}{*}{$\begin{array}{l}\text { Three-step etch- } \\
\text { and-rinse adhesive }\end{array}$} & \multirow{2}{*}{$\begin{array}{l}\text { Gel Etchant; } \\
\quad-31297\end{array}$} & & Etching: $37,5 \%$ phosphoric acid. \\
\hline & & & $\begin{array}{c}\text { Primer: HEMA, 2-[2-(methacryloyloxy)ethoxycarbonyl] benzoic acid, } \\
\text { GPDM, ethanol, water, photoinitiator }\end{array}$ \\
\hline & $\begin{array}{l}\text { OptiBond FL; } \\
-31297\end{array}$ & & $\begin{array}{l}\text { Bond: HEMA, 3-trimethoxysilylpropyl methacrylate, 2-hydroxy-1,3- } \\
\text { propanediyl bismethacrylate, alkali fluorosilicates }(\mathrm{Na}) \text {, photoinitiator. }\end{array}$ \\
\hline \multirow{2}{*}{$\begin{array}{l}\text { High-viscosity } \\
\text { bulk-fill composite } \\
\text { resin }\end{array}$} & \multirow{2}{*}{$\begin{array}{l}\text { Tetric EvoCeram Bulk } \\
\text { Fill, Shade IVA; } \\
\quad \text { (R04686) }\end{array}$} & \multirow{5}{*}{$\begin{array}{l}\text { Ivoclar Vivadent AG, } \\
\text { Schaan, Liechtenstein }\end{array}$} & $\begin{array}{c}\text { Composite: Bis-GMA, UDMA, Bis-EMA, barium aluminium glass, } \\
\text { ytterbium trifluoride, oxide and prepolymers. }\end{array}$ \\
\hline & & & Filler loading $80 \% \mathrm{w}+\%$ and 60 vol\% \\
\hline \multirow{3}{*}{$\begin{array}{l}\text { Two-step etch-and- } \\
\text { rinse adhesive }\end{array}$} & \multirow{2}{*}{$\begin{array}{l}\text { Total Etch Gel; } \\
\quad \text { (R39845) }\end{array}$} & & Etching: $37 \%$ phosphoric acid \\
\hline & & & $\begin{array}{l}\text { Bond: Bis-GMA, ethanol, HEMA, phosphoric acid acrylate, UDMA, } \\
\text { diphenyl(2,4,6- trimethylbenzoyl) phosphine oxide. }\end{array}$ \\
\hline & $\begin{array}{l}\text { Tetric N-Bond; } \\
\quad \text { (R27602) }\end{array}$ & & \\
\hline \multirow{2}{*}{$\begin{array}{l}\text { Low-viscosity bulk- } \\
\text { fill composite resin }\end{array}$} & SureFil SDR Flow, & \multirow{5}{*}{$\begin{array}{l}\text { Dentsply Caulk, } \\
\text { Mildford, USA }\end{array}$} & $\begin{array}{l}\text { Composite: Modified UDMA, dimethacrylate, trimethacrylate, barium- } \\
\text { and strontium-aluminofluoro-borosilicate glass. }\end{array}$ \\
\hline & $\begin{array}{l}\text { Shade Universal; } \\
-8153\end{array}$ & & Filler loading $68 w+\%$ and 45 vol\% \\
\hline \multirow{3}{*}{$\begin{array}{l}\text { Two-step etch-and- } \\
\text { rinse adhesive }\end{array}$} & \multirow{3}{*}{$\begin{array}{l}\text { Etching Dental Gel; } \\
\quad(671857 \mathrm{E})\end{array}$} & & Etching: 34\% phosphoric acid. \\
\hline & & & $\begin{array}{l}\text { Bond: UDMA, TEGDMA, HEMA, butyl alcohol, dipentaerythritol } \\
\text { pentaacrylate phosphate, carboxylic acid modified dimethacrylate. }\end{array}$ \\
\hline & & & \\
\hline \multirow{2}{*}{$\begin{array}{l}\text { Low-viscosity bulk- } \\
\text { fill composite resin }\end{array}$} & $\begin{array}{l}\text { Filtek Bulk Fill } \\
\text { Flowable Restorative, }\end{array}$ & & $\begin{array}{c}\text { Composite: Bis-GMA, Bis-EMA, UDMA, TEGDMA, substituted } \\
\text { dimethacrylate, EDMAB, benzotriazol, silate treated ceramic, ytterbium } \\
\text { trifluoride }\end{array}$ \\
\hline & $\begin{array}{l}\text { Shade A2; } \\
-402919\end{array}$ & 3M ESPE, St. Paul, USA & Filler loading $64.5 \mathrm{wt} \%$ and 42.5 vol\% \\
\hline $\begin{array}{l}\text { One-step self-etch } \\
\text { adhesive }\end{array}$ & $\begin{array}{l}\text { Scotchbond } \\
\text { Universal; } \\
-482988\end{array}$ & & $\begin{array}{c}\text { Bond: MDP, Bis-GMA, HEMA, phosphate monomer, dimethacrylate } \\
\text { resins, methacrylate-modified polyalkenoic acid copolymer, filler, } \\
\text { ethanol, water, initiators, silane treated silica }\end{array}$ \\
\hline
\end{tabular}

a:Information applied by the manufacturer; Bis-GMA: bisphenol-A diglycidyl ether dimethacrylate; TEGDMA: triethyleneglycol dimethacrylate; HEMA: 2-hydroxyethyl methacrylate; GPDM: glycerol phosphate dimethacrylate; UDMA: urethane dimethacrylate; Bis-EMA: ethoxylated bisphenol-A dimethacrylate; EDMAB: ethyl 4-dimethyl aminobenzoate; MDP: 10-methacryloyloxydecyl dihydrogen phosphate.

Brazil) and finished with a fine diamond bur (FG\#3145FF, KG Sorensen). The bur was attached to a high-speed air turbine hand piece (Kavo, Joinville, Brazil), and the preparations were made under water cooling

Preparations were randomly assigned to one of four groups $(\mathrm{n}=10)$, according to the restorative system used. Each adhesive system was applied to the preparations and light cured. During composite placement, a Teflon matrix having the same dimensions of the cavity ( $4 \mathrm{~mm}$ length $\times 3 \mathrm{~mm}$ width $\times 2 \mathrm{~mm}$ height) was positioned over the occlusal surface in order to provide a total of $4 \mathrm{~mm}$ height to composite restorations, with a $\mathrm{C}$-factor of 1 . The matrix was used to avoid the risk of pulpal chamber exposure during the cavity preparation, and it also allowed a thicker remaining dentin in the cavity floor to be gripped during the MTBS test. The conventional composite (HER) was placed in four, wedge-shaped, oblique increments (approximately $2 \mathrm{~mm}$ thick), and each increment was separately light-activated for $20 \mathrm{~s}$. The bulk-fill composites (TEC, SDR, and FBF) were placed in a single increment $4 \mathrm{~mm}$ thick, and light cured for 20s. The Teflon upper mold was carefully removed after light-activation of each specimen. 
After 24 hours of water storage at $37^{\circ} \mathrm{C}$, specimens were serially sectioned using a low-speed diamond blade (Isomet Diamond Wafering Blades, Buehler Ltd., Lake Buff, USA) with water cooling, to produce eight parallel-sided sticks ( $0.9 \mathrm{~mm}$ wide $\mathrm{x} 0.9 \mathrm{~mm}$ thick) free of dentin on the sides. Four sticks from each tooth were selected randomly for immediate testing $(24 \mathrm{~h})$, and the four remaining sticks were tested after one year of storage in distilled water at $37^{\circ} \mathrm{C}$.

For MTBS testing, the sticks were fixed to a jig with cyanoacrylate glue in a universal testing machine (EZ Test, Shimadzu, Kyoto, Japan), and subjected to a tensile force at a crosshead speed of $1 \mathrm{~mm} / \mathrm{min}$ until the failure occurred. After bond strength testing, their cross-sectional areas were measured. The maximum tensile load of the recorded failure (Kgf) was divided by the respective cross-sectioned area of each stick, and converted into bond strength (MPa). A single failure stress value was calculated for each tooth and testing time by averaging the values of sticks from that tooth.

The fractured specimens were mounted on stubs, gold-coated (MED 010, Balzers, Balzer, Liechtenstein), and examined using a scanning electron microscope (SEM) (JSM-5600LV, JEOL Inc., Tokyo, Japan) at 400x magnification (voltage: $15 \mathrm{kV}$; beam width: $25-30 \mathrm{~nm}$; working distance: 10-20 mm). Failure mode of each beam was classified as follows: a. cohesive failure in dentin; $b$. adhesive failure between adhesive layer and dentin; c. cohesive failure in hybrid layer; $d$. cohesive failure in adhesive; e. adhesive failure between adhesive layer and composite; $\mathrm{f}$. cohesive failure in composite; g.mixed failure of dentin, adhesive, and composite.

\section{Optical coherence tomography (OCT) system}

Swept-source OCT (Santec OCT-2000, Santec Co., Komaki, Japan) was used to evaluate the interfacial adaptation of the restorative materials, and the set-up components used were the same as described by Shimada et al. ${ }^{12}$.

\section{Interfacial adaptation (IA) imaging}

Sixteen teeth were used for IA evaluation. Standardized Class I preparations were made: $3 \mathrm{~mm}$ diameter $\times 1.5 \mathrm{~mm}$ deep, with rounded margins located in occlusal enamel and with $2 \mathrm{~mm}$ diameter at the cavity floor located in dentin, with tapered axial walls angled at approximately 130 degrees that were created using a flat-end, tapered cylinder diamond bur (custommade FG\#3132, KG Sorensen) and finished with a fine diamond bur (FG\#3132F, KG Sorensen). Due to the limitation of the OCT system in light penetration depth, the preparations were made with $1.5 \mathrm{~mm}$ depth. The resulting C-factor for IA specimens was 2.1.

The prepared teeth were randomly assigned into the four groups $(\mathrm{n}=4)$. Each adhesive system was applied to the preparations and light cured. All preparations were restored using a single composite increment with its respective composite, and cured for $20 \mathrm{~s}$. After polymerization, the occlusal surfaces of all specimens were lightly polished using 2000-grit silicon carbide paper, to remove excess resin composite and to standardize the occlusal surface.

After $24 \mathrm{~h}$ water storage at $37^{\circ} \mathrm{C}$, all the specimens were examined using OCT. During the scan, the probe connected to the OCT was set at a fixed distance over the restoration surface, with the scanning beam oriented 90 degrees to the restoration occlusal plane. Cross-sectional 2D images of each restoration were recorded at $500-\mu \mathrm{m}$ intervals by moving the sample through the laser beam in a mesio-distal direction. Five cross-sectional images were obtained from each restoration, totaling 20 images per material.

If any air is present within a defect at the interface between restorative material and dentin, reflection of a portion of laser light at the interface between two media having different refractive indices occurs, and it is visualized as bright areas in the OCT image. In order to evaluate the IA of different restorative systems, OCT 2D raw tomograms were imported into image analysis software (NIH ImageJ 1.60, Bethesda, USA) and a median filter (1px radius) was applied to reduce background noise. ${ }^{13,14}$ A JAVA-based plugin for ImageJ, having an algorithm to determine signal threshold, was used for the image analysis. The percentage of brighter pixels (gap) with significantly higher signal intensity compared to surrounding pixels at the interfacial area was automatically calculated on the cross-sectional OCT 2D image (Figure 1). This imaging analysis method and the algorithm have been described in detail elsewhere. ${ }^{15}$ 

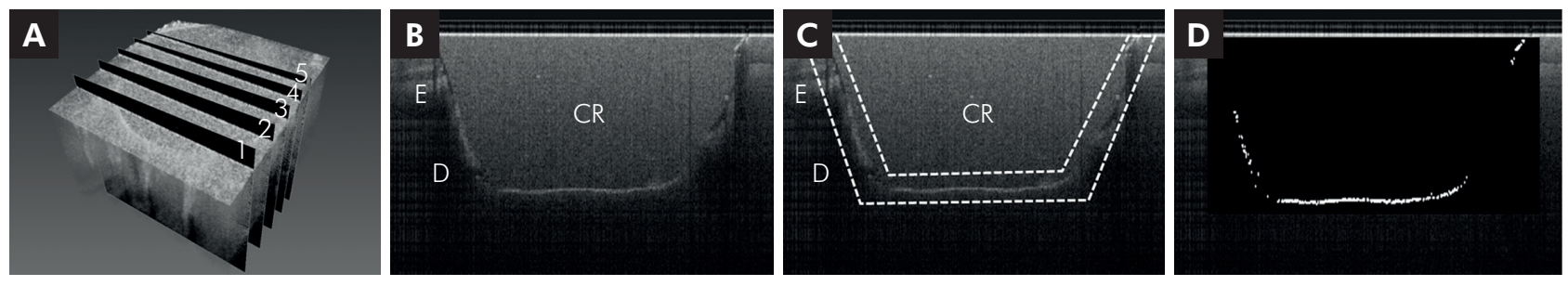

Figure 1. (a) Five 2D images were obtained from sample by OCT scanning at 500- $\mu$ m intervals. (b) Representative 2D OCT image slice. (c) Standardized selection of the interfacial area with an increased signal value to be analyzed by the software. (d) The total percentage of brighter pixels, represented in white, over the entire interfacial zone was calculated using an Image plugin (i.e. 63\% interfacial gap). The mean of five cross-sectional images were calculated per sample. Abbreviations: CR, composite resin; E, enamel; D, dentin

\section{Confocal laser scanning microscopy (CLSM)}

To confirm the presence of a gap or defect within the restorative material-dentin interface, representative specimens of each material were chosen for direct cross-sectional observation using CLSM (1LM21H/W, Lasertec Co., Yokohama, Japan). Middle cross-sectional OCT images were recorded, and two points along the OCT imaging plane were marked on the tooth surface using a marker pen. The tooth crown was then axially trimmed off using wet silicon carbide papers (600 to 2000-grit) to reach the section with the marked points. The surface was further polished with diamond pastes with particle sizes down to $0.25 \mu \mathrm{m}$ under running water. In this manner, cross-section of the investigation site was prepared at an approximate location imaged by OCT. Polished specimens were subsequently observed with CLSM at a 1250x magnification.

\section{Statistical analysis}

Mean MTBS values were analyzed using two-way analysis of variance (ANOVA): restorative system (4 levels) and storage time (2 levels), and the percentage of interfacial gap formation values were analyzed using one-way ANOVA. Tukey and Dunnett's T3 post-hoc tests were performed for MTBS and gap percentage values for pair-wise means comparisons, respectively. All statistical analyses were performed using statistical software (Statistical Package for Social Sciences, SPSS for Windows, Version 16.0, SPSS, Chicago, USA) with significance level defined as $\alpha=0.05$.

\section{Results}

Means and standard deviations of MTBS and percentage of gap values obtained are presented in
Table 2 and 3, respectively. For the MTBS, the two-way ANOVA showed that bond strength results were influenced significantly by the restorative system used $(p<0.0001)$ and by storage period $(p=0.0157)$. The interaction of these two factors was not significant ( $p$ $=0.5549$ ). Tukey's post-hoc test revealed the presence of statistically significant differences between MTBS results after 24 hours or one year of water storage. For both storage periods, FBF/SBU showed significantly lower MTBS values, while no significant differences were observed among HER/OBF, TEC/TNB, and $\mathrm{SDR} / \mathrm{XPB}$. There was a significant decrease in MTBS values after one year of storage $(p<0.05)$, within all restorative systems tested.

Failure modes are summarized in Figure 2. Representative SEM micrographs of each failure mode pattern are shown in Figure 3. The mixed failure mode (VII; Figure 3f) predominated for all materials within both storage periods. Cohesive failures at the hybrid layer (III; Figure 3c), cohesive failures in the adhesive layer (IV; Figure 3d), and cohesive failures in the composite (VI; Figure 3e) were observed in most test groups after 24 hours and one-year storage. No specific mode of adhesive failure between adhesive layer and composite (V) was found at 24 hours. After one year of water storage, cohesive failure in dentin (I; Figure 3a) was only observed for HER/OBF, while FBF/SBU showed an increased incidence of adhesive failure between adhesive layer and dentin (II; Figure 3b). Similar failure mode patterns were observed for HER/OBF and SDR/XPB, when compared after $24 \mathrm{~h}$ and $1 \mathrm{y}$ storage.

For the IA evaluation, no statistically significant difference in gap percentage was found between TEC/ TNB and FBF/SBU after 24 hours ( $p>0.05$ ), while $\mathrm{SDR} / \mathrm{XPB}$ showed significantly lower values than that 
of HER/OBF ( $p$ < 0.05). Representative OCT images of each material and their corresponding CLSM images are shown in Figures 4 to 7. Additionally, high magnification of CLSM images at the adhesive-dentin

Table 2. Mean MTBS of different restorative systems applied to dentin.

\begin{tabular}{ccc}
\hline \multirow{2}{*}{ Restorative system } & \multicolumn{2}{c}{ MTBS (MPa) } \\
\cline { 2 - 3 } HER/OBF & 24 hours & One year \\
TEC/TNB & $49(1)^{A, a}$ & $40(10)^{B, a}$ \\
SDR/XPB & $38(9)^{A, a}$ & $38(4)^{B, a}$ \\
FBF/SBU & $24(10)^{A, b}$ & $36(4)^{B, a}$ \\
\hline
\end{tabular}

Data are presented as the mean (standard deviation) in MPa. Identical upper-cased letter in a row (comparing storage times for the same restorative systems) and lower-cased letter in a column (comparing restorative systems within the same storage time) indicate the absence of any statistically significant difference among values $(p<0.05)$.

Table 3. Mean brightness values (\%) at the interfacial zone between dentin and restorative systems.

\begin{tabular}{lc}
\hline & $\begin{array}{c}\text { Percentage of brighter pixels } \\
\text { Restorative system }\end{array}$ \\
\cline { 2 - 2 } & (GAP \%) \\
\hline HER/OBF & 24 hours \\
TEC/TNB & $11(8)^{b}$ \\
SDR/XPB & $39(18)^{a}$ \\
FBF/SBU & $5(3)^{c}$ \\
\hline
\end{tabular}

Data are presented as the mean (standard deviation). Identical letters indicate the absence of any statistically significant differences among values $(p<0.05)$. interface are shown in Figure 8. Brighter areas at the resin-dentin interface represent the presence of a gap or a defect, which were confirmed by CLSM images. Fewer areas of increased brightness were observed along the interface of HER/OBF and SDR/XPB (Figures 4 and 6) compared to TEC/TNB and FBF/SBU (Figures 5 and 7), indicating a better bonding adaptation.

\section{Discussion}

The null hypotheses, that there would be no significant difference in MTBS or IA values of bulk-fill restorative systems compared to a conventional restorative system, was rejected. FBF/SBU showed lower MTBS values than that obtained with HER/OBF for both storage periods. Furthermore, TEC/TNB and $\mathrm{FBF} / \mathrm{SBU}$ presented significantly higher percentages of gap formation compared to HER/OBF, while SDR/XPB provided better marginal adaptation.

In this study, the bonding measurement of small areas were obtained by MTBS testing. ${ }^{16}$ This method generated multiple beams from a single tooth which were divide for evaluation after two storage periods. Additionally, OCT was used to nondestructively evaluate the internal adaptation of different restorative materials and to quantify micrometer gaps under composite restorations. ${ }^{13,14,17}$ It is important to note

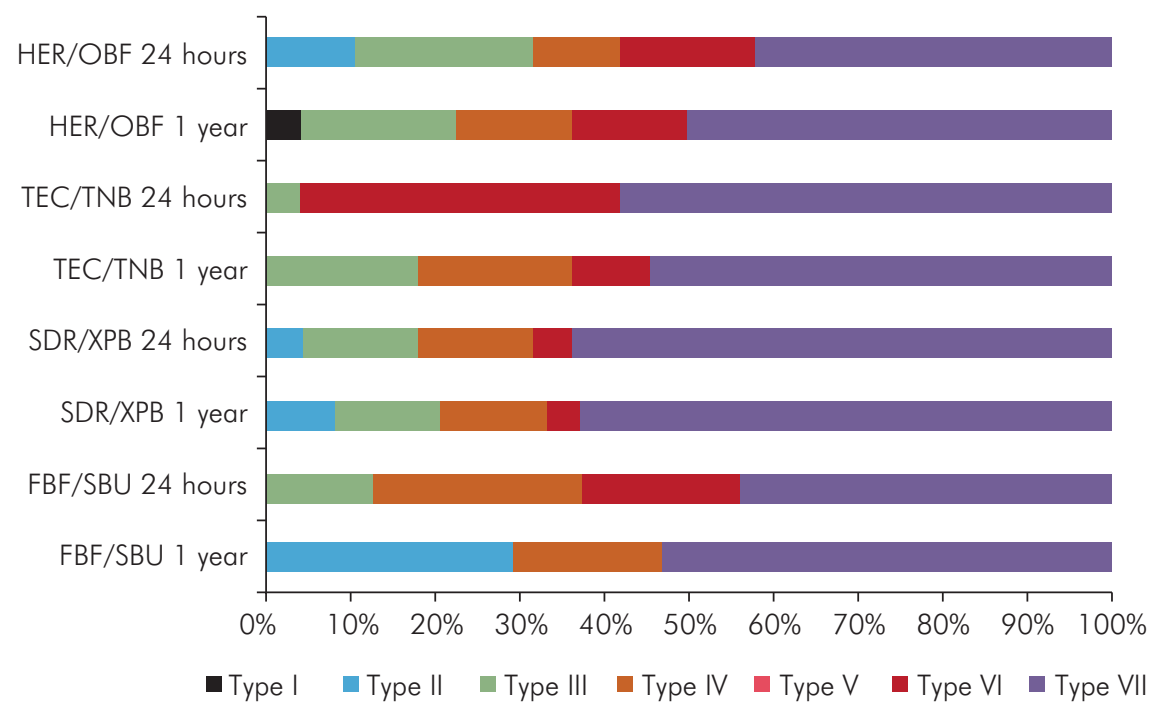

Figure 2. Distribution (\%) of failure modes of the restorative systems after $24 \mathrm{~h}$ and $1 \mathrm{y}$ of water storage. 

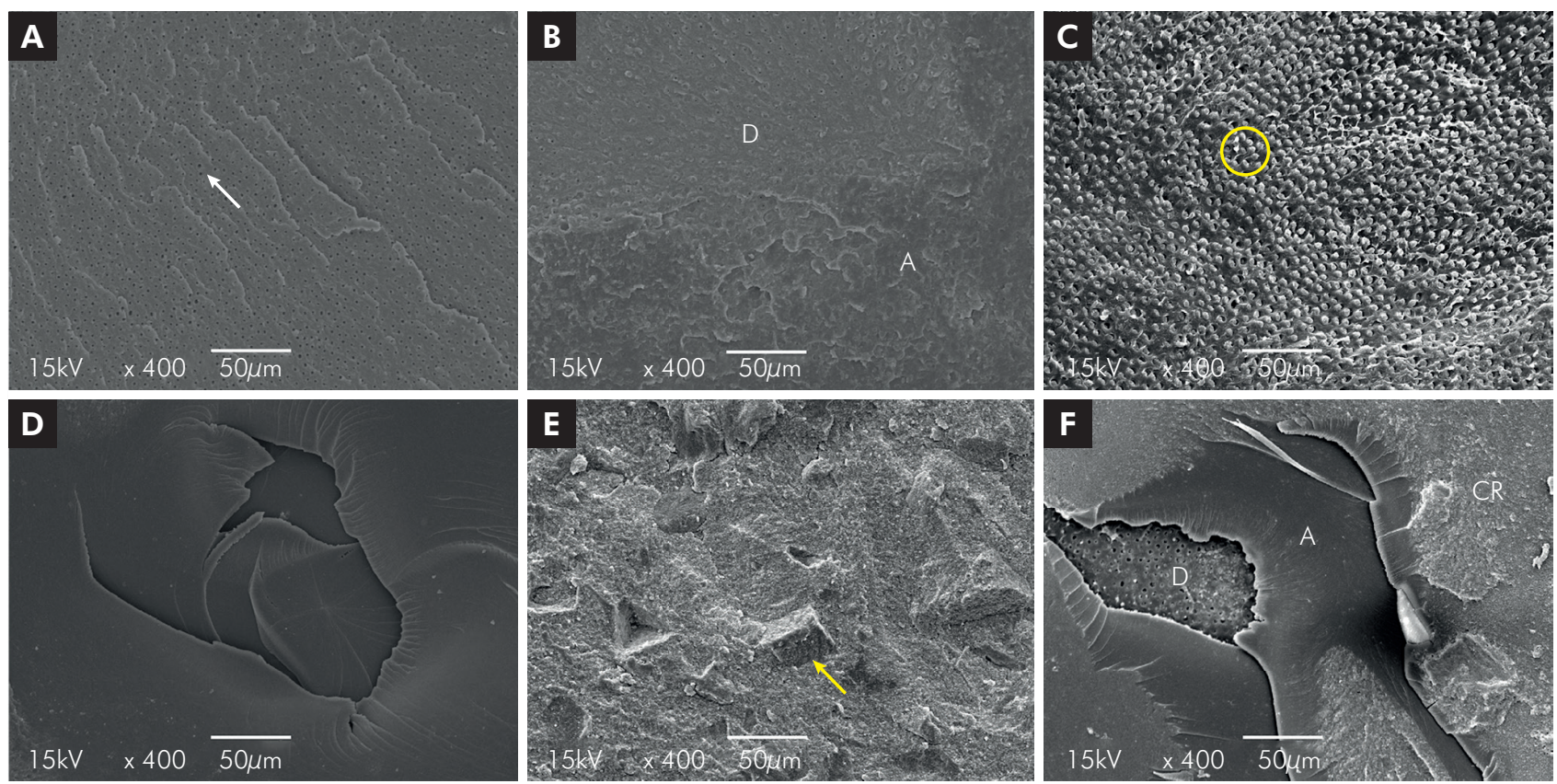

Figure 3. SEM micrographs of representative fracture patterns. (a) Type I (HER/OBF - ly storage). Cracks within the dentin substrate, and small open dentinal tubules can be seen (white arrow); (b) Type II (FBF/SBU - 1y storage). Smear plugs and a thin layer of adhesive are present; (c) Type III (HER/OBF - 24h storage). Circled area shows resin tags remaining in dentinal tubules; (d) Type IVSDR/XPB - 24h storage). Scale-like structures can be seen in the fractured adhesive layer; (e) Type VI (SDR/XPB - 1y storage). Filler particles from the composite can be seen (yellow arrow); (f) Type VII (TEC/TNB - ly storage).

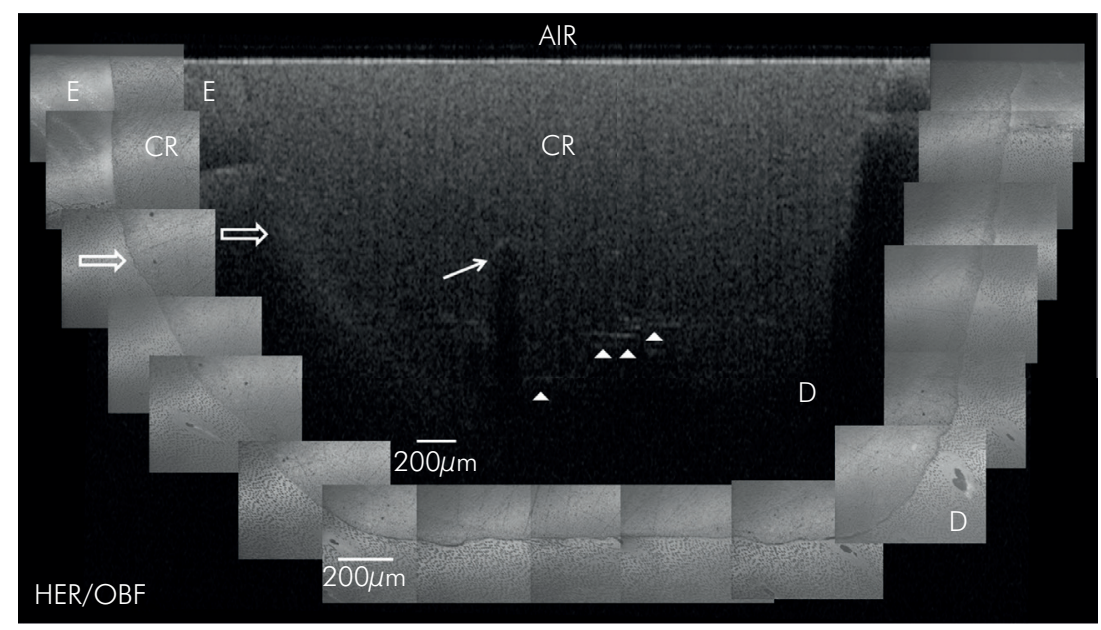

Figure 4. Representative 2D OCT image of HER/OBF and its corresponding CLSM image. Almost no increase in signal intensity (brighter pixels) were observed at the interface, indicating a good sealing ability as pointed by the blank arrow. A void could be observed in the OCT image as pointed by the arrow at the composite. Bold arrowheads are pointing toward defects at the composite, suggesting phase separation inside the composite.

that the limitation of current OCT systems is the light penetration depth, which is approximately 2 to $3 \mathrm{~mm}$ for conventional direct composites. ${ }^{18}$ Thus, in order to assure optimal OCT imaging conditions, the specimens were restored in $1.5 \mathrm{~mm}$ deep cavities for IA evaluation.

The control group, HER/OBF, is considered the "gold standard" bonding agent within etch-and- 


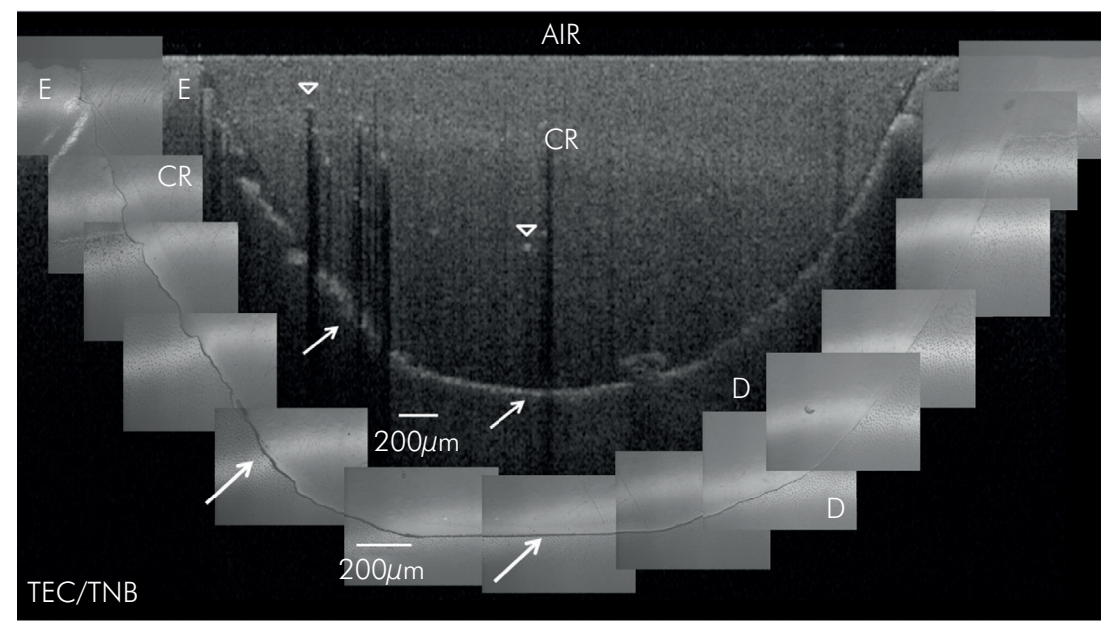

Figure 5. Representative 2D OCT image of TEC/TNB and its corresponding CLSM image. Interfacial gaps, which exhibited brighter pixels in the OCT images, were confirmed by CLSM as pointed by the arrows. Due to the loss in signal intensity underneath possibly larger filler particles (blank arrow heads), part of the interface in the OCT was masked.

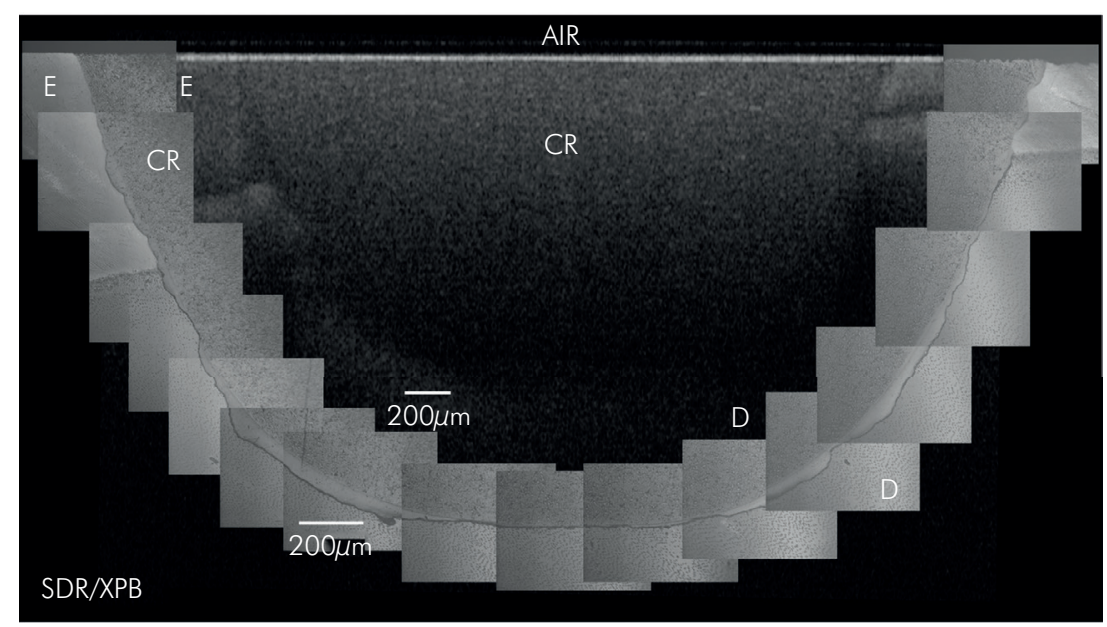

Figure 6. Representative 2D OCT image of SDR/XPB and its corresponding CLSM image. Almost no increase in signal intensity (brighter pixels) were observed at the interface. The OCT and CLSM images indicated a good interfacial adaptation.

rinse adhesive systems. ${ }^{19}$ It has been suggested that optimized hybrid layer formation at the demineralized intertubular dentin and the filled bonding resin applied over the primed dentin surface contribute to reinforcing physical properties. ${ }^{20}$ Along with the OBF adhesive system, the specimens were restored with HER using an oblique layering application. This incremental filling technique has been previously reported to reduce gap formation. ${ }^{6}$ Indeed, these properties could explain the high MTBS values observed for this group, and the bond failure location analysis, which was predominantly a mix of dentin, adhesive, and composite, for both storage periods. But no significant differences in MTBS values among HER/OBF, TEC/TNB, or SDR/XPB were observed, when compared within the same storage period. Differently than in the MTBS, for the IA evaluation, the HER/OBF specimens were restored using a single increment. Although the IA results cannot be directly compared with the MTBS findings due to the different methods applied in this study, HER/ OBF also showed good bonding properties regarding the IA evaluation, with low gap formation found at $1.5 \mathrm{~mm}$ thickness. 


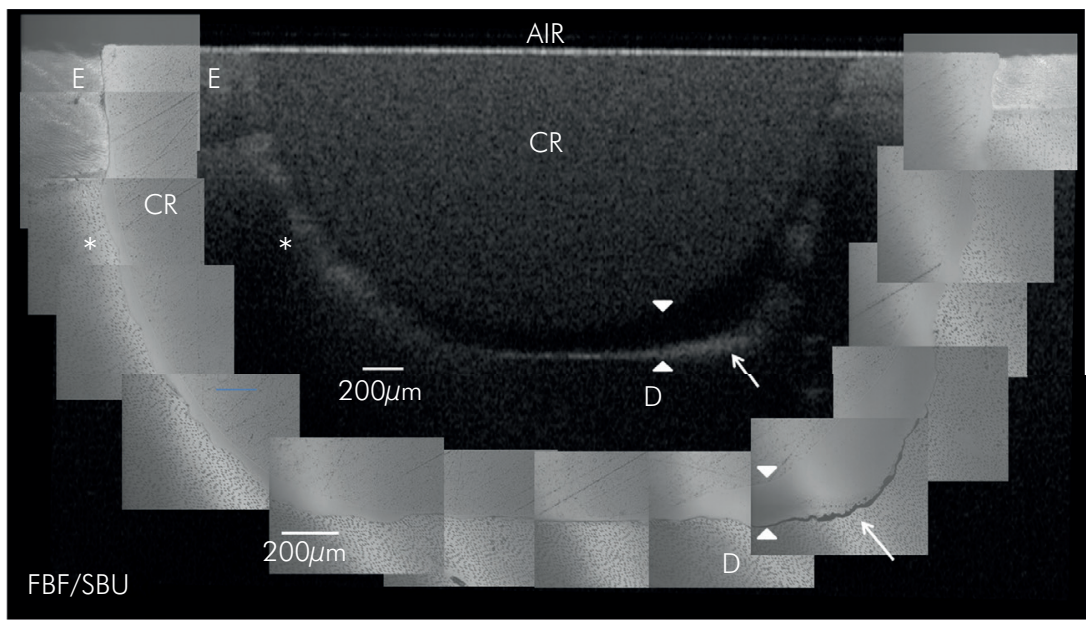

Figure 7. Representative 2D OCT image of FBF/SBU and its corresponding CLSM image. Interfacial gaps, which exhibited higher brighter pixels in the OCT images, were confirmed by CLSM as pointed by the arrows. The asterisk shows interfacial areas with bright pixels, however they are not considered as gap. It most probably indicates areas with adhesive penetration. Arrow heads are pointed toward the adhesive layer, corresponding to $90 \mu \mathrm{m}$ in CLSM images.
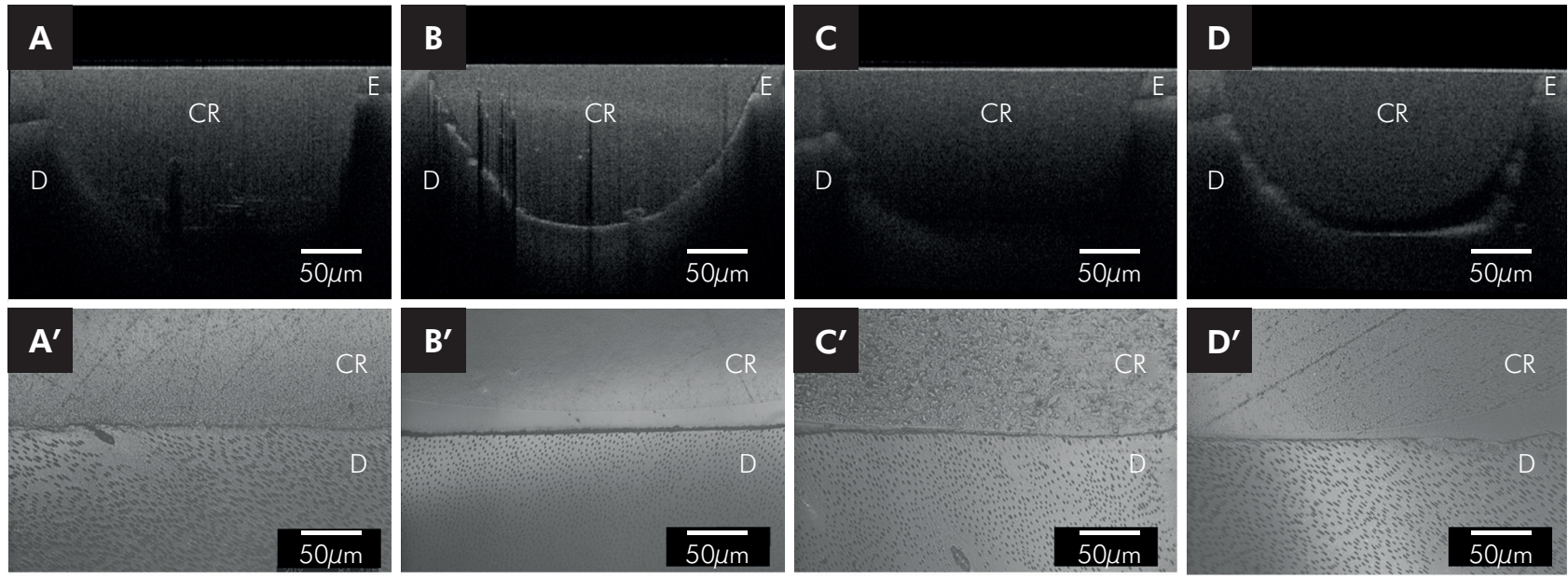

Figure 8. Representative 2D OCT image slices of each restorative system (a-d) and the corresponding CLSM ( $a^{\prime}$ - $\left.d^{\prime}\right)$. The presence of gaps at the bottom of the restorations are better visualized with CLSM at a 1250x magnification. Images are ordered as follows: $\left(a, a^{\prime}\right)$ HER/OBF; (b, b') TEC/TNB; $\left(c, c^{\prime}\right)$ SDR/XPB; $\left(d, d^{\prime}\right)$ FBF/SBU.

The TNB adhesive system requires prior acid etching on dentin; however, primer and bonding components are combined into a single solution, and are then applied to the tooth surface. During the application of simplified etch-and-rinse adhesives, a certain amount of water is crucial to prevent the collagen network from collapsing and to allow proper resin monomer infiltration. ${ }^{21}$ In a recent study, ${ }^{22}$ significantly lower shrinkage stress and gap formation (32.9\%) were observed for TEC compared to other bulk-fill restorative materials. However, a lower degree of conversion was observed at the bottom of the restoration, which may have contributed to the reduction in the magnitude of shrinkage stress and percentage of gap formation. It is noteworthy that 4-mm deep preparations were used for MTBS evaluation, while only 1.5-mm deep cavities were used for IA evaluation, in the current study. Thus, a higher degree of conversion is expected in the 1.5-mm deep cavity restoration and in turn, may result in higher 
shrinkage stress of the composite and competing forces with the dentin-resin interface, leading to debonding at the restoration bottom, and defects at the interfacial area. ${ }^{23}$ These factors might explain the results in the current study, in which significantly higher gap formation for TEC/TNB was observed compared to the control group. Conversely, similar MTBS values were observed for TEC/TNB as for the control group, during both storage periods.

The XPB bonding mechanism is also based on hybridization in the moist dentin environment. Meanwhile, SDR bulk-fill composite contains a modified UDMA with a photoactive group incorporated into the monomer chain, which helps to delay gelation and reduce shrinkage stress without affecting the degree of conversion. This UDMA also has higher molecular weight $(849 \mathrm{~g} / \mathrm{mol})$ than other commonly-used monomers, such as Bis-GMA (512 g/mol), Bis-EMA (496 g/mol) and conventional UDMA (470 g/mol). Thus, the shrinkage itself can be reduced by decreasing the number of reactive sites per unit volume. ${ }^{24}$ Moreover, studies have reported good marginal adaptation ${ }^{22}$, low volumetric shrinkage, ${ }^{25}$ and low shrinkage stress ${ }^{26}$ for this material. In a previous OCT study, ${ }_{17}^{17}$ SDR also showed better performance regarding sealing ability. These findings corroborate the results of the current study, in which SDR/XPB was the only bulk-fill material that presented similar MTBS values to the control group, and with the lowest gap percentage.

SBU adhesive contains 10-methacryloyloxydecyl dihydrogen phosphate (10-MDP), HEMA, and Bis-GMA. The MDP monomer interacts with hydroxyapatite and forms a hydrolytically stable bond with calcium. ${ }^{27}$ Indeed, a recent study reported that high MTBS values were observed for SBU bonded to flat dentin after short- and long-term storage. ${ }^{28}$ Conversely, in the present study, FBF/SBU showed the lowest bond strength values for both storage periods. This finding might be explained by the fact that in most of the studies, bonding was performed on the middle dentin portion, while deep dentin was used in the current study. ${ }^{29}$ In deep preparations, dentin presents less intertubular area and higher moisture. Thus, only a small solid dentin area is available for hybridization, consequently producing lower bond strengths. ${ }^{30}$ This property may partially support the assumption that SBU adhesive is more sensitive to variations in the presence of calcium from hydroxyapatite, because SBU contains MDP monomer.

Meanwhile, FBF includes Bis-GMA, UDMA, TEGDMA, and bisphenol-A polyethylene glycol diether dimethacrylate (Bis-EMA). According to the manufacturer, by adjusting the proportions of high molecular weight monomers, FBF can produce low polymerization shrinkage with a low modulus development, resulting in low stress. In contrast, in a recent study, ${ }^{22} \mathrm{FBF}$ showed higher polymerization stress values with increased internal gap formation compared to HER. These findings could explain the results obtained in the current study, in which FBF/SBU showed significantly lower MTBS and greater gap formation compared to all materials tested.

Interestingly, all materials showed significant decreases in MTBS within the restorative system after long-term storage. This phenomenon may be related to the hydrophilicity of HEMA, which is found in the composition of all adhesives tested. Although HEMA enhances wetting of the dentin and is an excellent adhesion-promoting monomer, ${ }^{29}$ it absorbs water, which can adversely compromise integrity and durability of the polymerized adhesive layer, ${ }^{26,31}$ especially when deep dentin surfaces are used for bonding.

Within the limitations of this study, highlighting in particular the different cavity configurations used for both tests, the MTBS and IA values revealed statistically significant differences among bulk-fill restorative systems when bonded to Class I preparations. However, several factors, such as the quality of adhesive systems and their bonding mechanism, ${ }^{29}$ along with the degree of conversion, volumetric shrinkage, and polymerization stress of the composites have also to be considered. ${ }^{32}$

\section{Conclusion}

Bulk-fill restorative systems are able to provide similar MTBS performance compared to a conventional restorative system, depending on the bonding strategy used. In the present study, when etch-and-rinse adhesives were compared there was 
no significant difference in MTBS among groups, only the self-etch system FBF/SBU demonstrated inferior values. Although, bond strength within all restorative systems were reduced after aging. Initial gap formation can be found in all materials, SDR/XPB bulk-fill presented better initial marginal adaptation compared to the conventional and the other bulk-fill systems evaluated.

\section{References}

1. Sideridou I, Tserki V, Papanastasiou G. Effect of chemical structure on degree of conversion in light-cured dimethacrylatebased dental resins. Biomaterials. 2002 Apr;23(8):1819-29. https://doi.org/10.1016/S0142-9612(01)00308-8

2. Ferracane JL. Developing a more complete understanding of stresses produced in dental composites during polymerization. Dent Mater. 2005 Jan;21(1):36-42. https://doi.org/10.1016/i.dental.2004.10.004

3. Cho E, Sadr A, Inai N, Tagami J. Evaluation of resin composite polymerization by three dimensional micro-CT imaging and nanoindentation. Dent Mater. 2011 Nov;27(11):1070-8. https://doi.org/10.1016/i.dental.2011.07.008

4. Carvalho RM, Pereira JC, Yoshiyama M, Pashley DH. A review of polymerization contraction: the influence of stress development versus stress relief. Oper Dent. 1996 Jan-Feb;21(1):17-24.

5. Versluis A, Douglas WH, Cross M, Sakaguchi RL. Does an incremental filling technique reduce polymerization shrinkage stresses? J Dent Res. 1996 Mar;75(3):871-8. https://doi.org/10.1177/00220345960750030301

6. Hansen EK. Effect of cavity depth and application technique on marginal adaptation of resins in dentin cavities. J Dent Res. 1986 Nov;65(11):1319-21. https://doi.org/10.1177/00220345860650110701

7. Umer F, Khan FR. Postoperative sensitivity in Class $\mathrm{V}$ composite restorations: comparing soft start vs. constant curing modes of LED. J Conserv Dent. 2011 Jan;14(1):76-9. https://doi.org/10.4103/0972-0707.80738

8. Hilton TJ, Schwartz RS, Ferracane JL. Microleakage of four Class II resin composite insertion techniques at intraoral temperature. Quintessence Int. 1997 Feb;28(2):135-44.

9. Son SA, Park JK, Seo DG, Ko CC, Kwon YH. How light attenuation and filler content affect the microhardness and polymerization shrinkage and translucency of bulk-fill composites? Clin Oral Investig. 2017 Mar;21(2):559-65. https://doi.org/10.1007/s00784-016-1920-2

10. Fronza BM, Ayres A, Pacheco RR, Rueggeberg FA, Dias C, Giannini M. Characterization of Inorganic Filler Content, Mechanical Properties, and Light Transmission of Bulk-fill Resin Composites. Oper Dent. 2017 Jul/Aug;42(4):445-55. https://doi.org/10.2341/16-024-L

\section{Acknowledgements}

This study was supported by grants from the State of São Paulo Research Foundation (FAPESP \#2013/05247-4 and 2012/18583-0), a Grant-in-Aid for Scientific Research (JSPS \#23390432 and 24792019) from the Japan Society for the Promotion of Science, and by a Research Grant for Longevity Sciences (\#21A-8), from the Ministry of Health, Labour, and Welfare.

11. Moszner N, Fischer UK, Ganster B, Liska R, Rheinberger V. Benzoyl germanium derivatives as novel visible light photoinitiators for dental materials. Dent Mater. 2008 Jul;24(7):901-7. https://doi.org/10.1016/i.dental.2007.11.004

12. Shimada Y, Sadr A, Burrow MF, Tagami J, Ozawa N, Sumi Y. Validation of swept-source optical coherence tomography (SS-OCT) for the diagnosis of occlusal caries. J Dent. 2010 Aug;38(8):655-65. https://doi.org/10.1016/i.jdent.2010.05.004

13. Makishi P, Shimada Y, Sadr A, Tagami J, Sumi Y. Nondestructive 3D imaging of composite restorations using optical coherence tomography: marginal adaptation of self-etch adhesives. J Dent. 2011 Apr;39(4):316-25. https://doi.org/10.1016/i.jdent.2011.01.011

14. Bakhsh TA, Sadr A, Shimada Y, Mandurah MM, Hariri I, Alsayed EZ et al. Concurrent evaluation of composite internal adaptation and bond strength in a class-I cavity. J Dent. 2013 Jan;41(1):60-70. https://doi.org/10.1016/i.jdent.2012.10.003

15. Bista B, Sadr A, Nazari A, Shimada Y, Sumi Y, Tagami J. Nondestructive assessment of current one-step self-etch dental adhesives using optical coherence tomography. J Biomed Opt. 2013 Jul;18(7):76020. https://doi.org/10.1117/1.JBO.18.7.076020

16. Pashley DH, Sano H, Ciucchi B, Yoshiyama M, Carvalho RM. Adhesion testing of dentin bonding agents: a review. Dent Mater. 1995 Mar;11(2):117-25. https://doi.org/10.1016/0109-5641(95)80046-8

17. Nazari A, Sadr A, Shimada Y, Tagami J, Sumi Y. 3D assessment of void and gap formation in flowable resin composites using optical coherence tomography. J Adhes Dent. 2013 Jun; 15(3):237-43.

18. Bakhsh TA, Sadr A, Shimada Y, Tagami J, Sumi Y. Noninvasive quantification of resin-dentin interfacial gaps using optical coherence tomography: validation against confocal microscopy. Dent Mater. 2011 Sep;27(9):915-25. https://doi.org/10.1016/j.dental.2011.05.003

19. De Munck J, Van Landuyt K, Peumans M, Poitevin A, Lambrechts $\mathrm{P}$, Braem $\mathrm{M}$ et al. A critical review of the durability of adhesion to tooth tissue: methods and results. J Dent Res. 2005 Feb;84(2):118-32. https://doi.org/10.1177/154405910508400204 
Evaluation of bulk-fill systems: microtensile bond strength and non-destructive imaging of marginal adaptation

20. Van Meerbeek B, Willems G, Celis JP, Roos JR, Braem $M$, Lambrechts $P$ et al. Assessment by nano-indentation of the hardness and elasticity of the resin-dentin bonding area. J Dent Res. 1993 Oct;72(10):1434-42. https://doi.org/10.1177/00220345930720101401

21. Cardoso MV, Neves AA, Mine A, Coutinho E, Van Landuyt K, De Munck J et al. Current aspects on bonding effectiveness and stability in adhesive dentistry. Aust Dent J. 2011 Jun;56 Suppl 1:31-44. https://doi.org/10.1111/j.1834-7819.2011.01294.x

22. Fronza BM, Rueggeberg FA, Braga RR, Mogilevych B, Soares LE, Martin AA et al. Monomer conversion, microhardness, internal marginal adaptation, and shrinkage stress of bulk-fill resin composites. Dent Mater. 2015 Dec;31(12):1542-51. https://doi.org/10.1016/i.dental.2015.10.001

23. Boaro LC, Fróes-Salgado NR, Gajewski VE, Bicalho $A A$, Valdivia AD, Soares CJ et al. Correlation between polymerization stress and interfacial integrity of composites restorations assessed by different in vitro tests. Dent Mater. 2014 Sep;30(9):984-92. https://doi.org/10.1016/i.dental.2014.05.011

24. Kim RJ, Kim YJ, Choi NS, Lee IB. Polymerization shrinkage, modulus, and shrinkage stress related to tooth-restoration interfacial debonding in bulkfill composites. J Dent. 2015 Apr;43(4):430-9. https://doi.org/10.1016/i.jdent.2015.02.002

25. Zorzin J, Maier E, Harre S, Fey T, Belli R, Lohbaver U et al. Bulk-fill resin composites: polymerization properties and extended light curing. Dent Mater. 2015 Mar;31(3):293-301. https://doi.org/10.1016/i.dental.2014.12.010
26. Kim RJ, Son SA, Hwang JY, Lee IB, Seo DG. Comparison of photopolymerization temperature increases in internal and external positions of composite and tooth cavities in real time: incremental fillings of microhybrid composite vs. bulk filling of bulk fill composite. J Dent. 2015 Sep;43(9):1093-8. https://doi.org/10.1016/i.ident.2015.07.003

27. Inoue S, Koshiro K, Yoshida Y, De Munck J, Nagakane K, Suzuki K et al. Hydrolytic stability of self-etch adhesives bonded to dentin. J Dent Res. 2005 Dec;84(12):1160-4. https://doi.org/10.1177/154405910508401213

28. Makishi P, André CB, Ayres A, Martins AL, Giannini M. Effect of storage time on bond strength and nanoleakage expression of universal adhesives bonded to dentin and etched enamel. Oper Dent. 2016 May-Jun;41(3):305-17. https://doi.org/10.2341/15-163-L

29. Giannini M, Makishi P, Ayres AP, Vermelho PM, Fronza BM, Nikaido T et al. Self-etch adhesive systems: a literature review. Braz Dent J. 2015 Jan-Feb;26(1):3-10. https://doi.org/10.1590/0103-6440201302442

30. Giannini M, Carvalho RM, Martins LR, Dias CT, Pashley DH. The influence of tubule density and area of solid dentin on bond strength of two adhesive systems to dentin. J Adhes Dent. 2001;3(4):315-24

31. Tay FR, Pashley DH. Water treeing: a potential mechanism for degradation of dentin adhesives. Am J Dent. 2003 Feb;16(1):6-12.

32. Stansbury JW. Dimethacrylate network formation and polymer property evolution as determined by the selection of monomers and curing conditions. Dent Mater. 2012 Jan;28(1):13-22. https://doi.org/10.1016/i.dental.2011.09.005 